\title{
A MEDIDA PROVISÓRIA 870/2019 E A DEMARCAÇÃO DE TERRAS INDÍGENAS.
}

\section{Tatiana Ferreira Lotfi ${ }^{1}$ \\ Thomaz Muylaert de Carvalho Britto ${ }^{2}$}

Publicada no primeiro dia do novo governo, em uma edição especial do Diário Oficial da União, a Medida Provisória 870/2019 (também chamada de MP da Reforma Administrativa) transferiu do Ministério da Justiça para o Ministério da Agricultura, Pecuária e Abastecimento as atribuições de identificar, delimitar, demarcar e registrar terras indígenas. Através da mesma MP, a Fundação Nacional do Índio (FUNAI), que antes pertencia ao Ministério da Justiça, passou a integrar a pasta do Ministério da Mulher, Família e Direitos Humanos.

No dia seguinte à publicação da MP e com a finalidade de regulamentá-la, o governo federal editou o Decreto 9.667/2019, determinando que a demarcação de terras tradicionalmente ocupadas por indígenas - função originalmente desempenhada pela FUNAI - ficaria a cargo da Secretaria Especial de Assuntos Fundiários (órgão criado para integrar o Ministério da Agricultura, Pecuária e Abastecimento).

Após reações de insatisfação de entidades civis, órgãos governamentais e instituições vinculadas à causa indígenas, em 09 de maio a MP 870/2019 foi submetida a votação pela Comissão Mista do Congresso Nacional e, por 15 votos a 9, os parlamentares decidiram que a demarcação de terras indígenas deveria voltar às atribuições da FUNAI e que o órgão indigenista voltaria a integrar a estrutura administrativa do Ministério da Justiça ${ }^{3}$.

Apesar de a votação aparentemente ter equacionado o caso, seu texto sinaliza em que sentido serão conduzidas as políticas indigenistas pelo atual governo. Para que desenvolvamos uma melhor compreensão sobre os direitos em risco e os interesses em jogo no texto da MP 870/2019, apresentaremos, de maneira sintética, o conceito de terra indígena e o procedimento de demarcação de terras sob encargo da FUNAI. Em

\footnotetext{
${ }^{1}$ Mestranda em Direito Constitucional no PPGDC-UFF.

${ }^{2}$ Mestrando em Direito Constitucional no PPGDC-UFF.

${ }^{3}$ Comissão aprova parecer que prevê volta da Funai para o Ministério da Justiça https://g1.globo.com/politica/noticia/2019/05/09/comissao-aprova-parecer-que-preve-volta-da-funai-parao-ministerio-da-justica.ghtml.
} 
seguida, cotejaremos os nossos comentários às críticas apresentadas em nota técnica do Ministério Público Federal ao texto da Medida Provisória.

De acordo com a FUNAI, terra indígena é "uma porção do território nacional, de propriedade da União, habitada por um ou mais povos indígenas, por ele(s) utilizada para suas atividades produtivas, imprescindível à preservação dos recursos ambientais necessários a seu bem-estar e necessária à sua reprodução física e cultural, segundo seus usos, costumes e tradições"4.

O art. 20, inc. XI da Constituição da República de 1988 (CR/88) inclui as terras indígenas entre os bens da União. Por serem bens da União, são terras inalienáveis, indisponíveis e os direitos que sobre elas recaem são imprescritíveis. Os Direitos Territoriais dos povos indígenas estão previstos no art. 231 da CR/88, que reconhece, além da organização social, costumes, línguas, crenças e tradições indígenas, os direitos originários sobre as terras que tradicionalmente ocupam.

A expressão "direitos originários" presente no texto constitucional tem relevante carga semântica. Afirmar o caráter "originário" de um direito significa reconhecer sua anterioridade à colonização e à publicação de normas jurídicas de matriz europeia. Por serem direitos originários, o procedimento administrativo de demarcação das terras indígenas tem natureza meramente declaratória. Isto quer dizer que os territórios indígenas não são criados pelo ato administrativo, e sim reconhecidos a partir de elementos técnico-jurídicos.

De acordo com o art. 231, $\S 2^{\circ}$ da Constituição Federal: "As terras tradicionalmente ocupadas pelos índios destinam-se a sua posse permanente, cabendolhes o usufruto exclusivo das riquezas do solo, dos rios e dos lagos nela existentes." Trata-se de um tipo específico de posse, de natureza originária e coletiva, que não se confunde com o conceito civilista de propriedade privada. O processo de demarcação das terras indígenas não altera o título de sua propriedade: elas continuam pertencendo à União, transferindo-se a posse o usufruto de suas riquezas às comunidades tradicionais.

Segundo dados da FUNAI, existem atualmente 462 terras indígenas regularizadas, localizadas em todos os biomas do território nacional e concentradas, em

4 FUNAI. Disponível em: http://www.funai.gov.br/index.php/nossas-acoes/demarcacao-de-terrasindigenas?limitstart=0\#. Acesso em 26/05/19. 
sua maioria, na Amazônia Legal ${ }^{5}$. Num país como o Brasil, em que há mais de 300 etnias indígenas distintas, a proteção aos seus territórios é um fator de unidade entre esses povos. Com o processo administrativo de demarcação das terras indígenas, a União estabelece uma política compensatória de desigualdades historicamente acumuladas, assegura a sobrevivência física dos habitantes originários de nossas terras e preserva sua diversidade cultural.

A FUNAI é o órgão indigenista oficial do Estado Brasileiro, criado pela Lei 5.371 de dezembro de 1967, sob a missão institucional de promover os direitos dos povos indígenas. Dentre as suas atribuições originárias, destaca-se a prestação de apoio e proteção social às comunidades indígenas contra ameaças à sua sobrevivência pelas práticas do garimpo ilegal, da exploração das florestas por madeireiras, da construção de barragens que provoquem alagamentos etc.

O procedimento administrativo de demarcação de terras indígenas está previsto na Lei $n^{\circ}$ 6.001/73 (Estatuto do Índio) e regulamentado pelo Decreto $n^{\circ} 1.775 / 96$, atribuindo-se à FUNAI a identificação, delimitação, demarcação física, homologação e registro de terras indígenas. O Decreto $\mathrm{n}^{\circ}$ 1.775/96 estabelece as distintas fases do processo administrativo, atribui publicidade ao procedimento para lhe assegurar transparência e teve sua constitucionalidade reconhecida pelo Supremo Tribunal Federal no MS no 24.045/2005. ${ }^{6}$

Por intermédio da FUNAI, a comunidade indígena interessada é diretamente envolvida em todas as fases e etapas de identificação e delimitação da terra indígena a ser administrativamente reconhecida. Equipes técnicas vinculadas ao órgão indigenista elaboram estudos de natureza antropológica, sociológica, jurídica, cartográfica e ambiental, os quais serão submetidos ao Presidente da FUNAI e, após aprovados, fundamentam o reconhecimento do direito originário através de uma Portaria Declaratória do Ministro da Justiça. Ato contínuo, compete ao Presidente da República homologar a demarcação através de um decreto.

\footnotetext{
5 FUNAI. Disponível em: http://www.funai.gov.br/index.php/nossas-acoes/demarcacao-de-terrasindigenas?limitstart=0\#. Acesso em 26/05/19.

6 Supremo $\quad$ Tribunal $\quad$ Federal. Disponível em: http://redir.stf.jus.br/paginadorpub/paginador.jsp?docTP=AC\&docID=86078. Acesso em 26/05/19.
} 
O texto da MP 870/2019 provocou reações de entidades civis e instituições de proteção à causa indígena, dentre as quais destacamos a Nota Técnica 01/2019, publicada pela $6^{\mathrm{a}}$ Câmara de Coordenação e Revisão sobre Populações Indígenas e Comunidades Tradicionais do Ministério Público Federal (MPF). Por meio desta nota técnica, O MPF sustentou a incompatibilidade entre a Medida Provisória 870/2019 e a Constituição de 1988 com base nos argumentos que apresentaremos ao longo deste comentário legislativo.

No ordenamento jurídico brasileiro, cabe ao Ministério Público a função de protetor das normas constitucionais. A Carta da República prevê expressamente a atribuição do referido órgão para salvaguardar os direitos indígenas. A Medida Provisória 870/2019 retirou a FUNAI do Ministério da Justiça e a transferiu para a pasta do Ministério da Mulher, Família e Direitos Humanos. Além disso, esvaziou a FUNAI de importantes atribuições, dentre as quais a identificação, delimitação e demarcação de terras indígenas, transferindo-as para o Ministério da Agricultura, Pecuária e Abastecimento.

Para o Ministério Público Federal (2019, p. 1), ao fazê-lo sem consultar previamente aos povos indígenas, a Medida Provisória 870/2019 ofende à Convenção 169 da Organização Internacional do Trabalho (OIT) e despreza a convergência entre os interesses indígenas e a preservação ambiental. Ratificada pelo Brasil em junho de 2002 através do Decreto Legislativo no 143/2002, a Convenção 169/OIT estabelece o dever de consulta prévia, livre e informada às comunidades indígenas dos países signatários sobre os assuntos que lhes digam respeito, devendo-se assegurar sua inclusão no processo de tomada de decisões.

Dispõe o art. 60, itens "1.a" e "2" da convenção que os Estados deverão consultar os povos indígenas sempre que forem elaboradas medidas administrativas ou legislativas suscetíveis de afetá-los diretamente, e que devem fazê-lo através de suas instituições representativas. No julgamento da Ação Direita de Inconstitucionalidade $\mathrm{n}^{\circ}$ 3.239, o Supremo Tribunal Federal reconheceu status constitucional à Convenção 169/OIT em virtude do seu conteúdo protetor aos direitos humanos.

Por sua natureza supralegal, os direitos garantidos pela Convenção constituem uma "etapa antecedente e obrigatória no procedimento de edição da MP n. 870/19, cuja 
inobservância enseja sua nulidade, naquilo que afeta os povos indígenas, por vício de convencionalidade" (2019, p. 9). O debate em questão deveria ter sido previamente viabilizado através de uma consulta (MPF, 2019, p. 8).

O instrumento de consulta prévia, dessa forma, reverbera a imprescindibilidade do diálogo entre o poder público e os povos indígenas, visto que os últimos são alijados, em muitas ocasiões, de qualquer possibilidade de manifestação política. A consulta prévia a uma decisão, especialmente no campo dos direitos das minorias, confirma o propósito constitucional de concessão de meios de participação direta na democracia representativa. Um dos exemplos, para tanto, consiste na iniciativa popular para a elaboração de leis. O Ministério Público Federal (2019, p. 11) frisa: "Não há, portanto, como argumentar pela existência de discricionariedade administrativa ou legitimidade política para afastar a aplicação do direito à consulta prévia”.

Além do desrespeito à consulta prévia e do esvaziamento das funções legais da FUNAI, ao transferir os estudos de demarcação de terras indígenas para o Ministério da Agricultura, Pecuária e Abastecimento, a MP 870/2019 sobrelevou interesses privados de ruralistas. Segundo SILVA (2018, p. 481), há uma relação entre o capitalismo e a demanda, pelo setor privado, em relação às terras indígenas.

A relação dos povos indígenas com suas terras tem matriz divina e sua vinculação com as florestas está relacionada com a sacralidade dos seus territórios. As terras indígenas são indispensáveis para a conservação dos seus costumes, para a preservação de suas culturas e até mesmo para o pleno exercício de sua liberdade religiosa. Suas inspirações e sabedorias são provenientes dos elementos da natureza, e seus territórios são fundamentais para o desenvolvimento de suas cosmovisões.

Por serem os guardiões das florestas, qualquer medida política ou jurídica que fragilize as demarcações indígenas traz em seu bojo uma ameaça à preservação ambiental. Os territórios indígenas demarcados são espécies de ilhas de cobertura vegetal na Amazônia Legal. Segundo levantamentos do Instituto Socioambiental, as 
terras indígenas funcionam como uma barreira ao desmatamento. Dos $20 \%$ de territórios devastados na região da Amazônia, menos de 2\% situam-se em áreas indígenas ${ }^{7}$.

A agenda do Ministério da Agricultura, Pecuária e Abastecimento, em contrapartida, está voltada à promoção dos interesses do agronegócio, ao desenvolvimento de projetos desenvolvimentistas e à apropriação de recursos naturais. Sob a ótica desenvolvimentista, a terra é vista como mercadoria e não como ambiente sagrado.

Tais interesses colidem frontalmente com a proteção das comunidades indígenas tradicionais e comprometem a efetividade das normas constitucionais voltadas à proteção dos povos indígenas. A demarcação de terras indígenas enseja disputas perante os interesses privados existentes em relação ao território sujeito ao procedimento (ARAÚJO JR., 2018, p. 275-276). A transferência da demarcação de terras indígenas para o Ministério da Agricultura representa evidente conflito de interesses e, assim, ofende à proteção constitucional.

No julgamento da Pet. 3.388, em 23/10/2009, o Supremo Tribunal Federal, através de seu relator Ministro Ayres Britto, afirmou o projeto de desenvolvimento social e ecologicamente equilibrado inaugurado pela Constituição da República, afirmando que:

\footnotetext{
"O desenvolvimento que se fizer sem ou contra os índios (...) desrespeita o objetivo fundamental do inciso II do art. 3o da Constituição Federal, assecuratório de um tipo de "desenvolvimento nacional" tão ecologicamente equilibrado quanto humanizado e culturalmente diversificado, de modo a incorporar a realidade indígena" 8 .
}

\footnotetext{
${ }^{7}$ Instituto Socioambiental: "Terras Indígenas seguem barrando desmatamento, mas situação de algumas áreas é crítica”. Disponível em: https://terrasindigenas.org.br/pt-br/node/49. Acesso em 03/06/19. ${ }^{8}$ Supremo Tribunal Federal. Pet $n^{\circ} .3388$, julgada em 23/10/2009, Rel. Ministro Ayres Britto. Disponível
em: http://redir.stf.jus.br/paginadorpub/paginador.jsp?docTP=TP\&docID=5214423. Acesso em 26/05/19.
} 
No que diz respeito ao meio ambiente, em sua nota técnica, o órgão ministerial afirmou a vedação ao retrocesso em matéria ambiental. $O$ meio ambiente ecologicamente equilibrado reputa-se como um direito constitucional de suma prioridade no ordenamento jurídico. A transferência das funções demarcatórias ao Ministério da Agricultura, Pecuária e Abastecimento, segundo o MPF, acarreta em comprometimento aos interesses indígenas e implica em retrocesso do seu arcabouço protetivo (MPF, 2019, p. 14).

Outro aspecto destacado pelo Ministério Público Federal em sua nota técnica é que MP 870/2019 não se limita a reorganizar administrativamente a administração pública, mas vai além e revisita a concepção assimilacionista do período ditatorial brasileiro, segundo a qual os índios são tuteláveis pelo Estado e a proteção dos seus interesses se contrapõe ao desenvolvimento econômico e à soberania nacional.

A política integracionista parte da premissa de que os índios são incapazes de se defender e, sob o discurso da proteção e assistência às comunidades indígenas, pretende inseri-los na sociedade nacional. O paradigma tutelar ignora as manifestações de vontade das comunidades originárias e desconsidera os riscos que sua incorporação à sociedade "desenvolvida" representa para a conservação de suas culturas e para a própria sobrevivência de seus indivíduos.

O texto da Constituição da República de 1988, quando enfatizou a autonomia dos povos indígenas e reconheceu o direito originário às terras tradicionalmente ocupadas em seu art. 231, pôs um fim ao paradigma assimilacionista e estabeleceu o vetor interpretativo de autodeterminação das comunidades indígenas, que possibilita apontar a inconstitucionalidade da MP 870/2019. No texto da Nota Técnica do MPF,

\begin{abstract}
A Medida Provisória 870/19, ao transferir a demarcação das terras indígenas ao Ministério da Agricultura, Pecuária e Abastecimento e a supervisão da Funai para o Ministério da Mulher, Família e Direitos Humanos operou a repristinação da velha política integracionista do direito antigo e obrigou os índios e suas comunidades a um falso tratamento isonômico em relação aos demais atores da sociedade brasileira, tratamento este que desconsidera e viola, a um só tempo, suas peculiaridades culturais e seus direitos constitucionais (MPF, 2019, p. 7).
\end{abstract}

A Constituição de 1988, em virtude de sua preocupação com a ordem social, manifestada na proteção aos direitos sociais, com a devida intervenção estatal para a 
garantia desses direitos, visou ao respeito perante a cultura indígena. A Carta Política compreende, em seu texto, direitos fundamentais, que não podem ter a sua eficácia comprometida em função de alterações na estrutura administrativa do Poder Executivo.

Feitas estas considerações, concluímos nossos comentários legislativos acerca da MP 870/2019 alinhados aos termos da Nota Técnica nº 01/2019 - 6 CCR do MPF. Consideramos que a proteção aos territórios indígenas é um fator de unidade entre as centenas de etnias indígenas existentes em nosso país e compreendemos que a identificação e demarcação de suas terras é um dever constitucional compensatório às desigualdades historicamente acumuladas pelos povos indígenas.

A publicação açodada de uma medida provisória que implique em tais reestruturações fere o dever de consulta prévia, livre e informada às comunidades indígenas sobre os assuntos que lhes digam respeito e as exclui do processo de tomada de decisões, contrapondo-se aos deveres assumidos pelo Estado Brasileiro na Convenção $\mathrm{n}^{\circ}$ 169/OIT. A consulta prévia aos povos indígenas se conforma ao propósito constitucional de ampliar meios de participação direta na democracia representativa, devendo ser observada e respeitada pelos três Poderes.

Entendemos que o procedimento administrativo de demarcação deve permanecer sob encargo da FUNAI eis que o órgão indigenista assegura que as comunidades jurídicas interessadas participem ativamente de todas as fases e etapas identificação e delimitação das terras a serem reconhecidas. A MP 870/2019, ao esvaziar tais funções da FUNAI e transferi-las para o Ministério da Agricultura, Pecuária e Abastecimento, despreza a vedação constitucional ao retrocesso ambiental e desmerece a convergência entre os interesses indígenas e a preservação ambiental.

Em acréscimo, ressaltamos o conflito de interesses entre a pauta do Ministério da Agricultura, Pecuária e Abastecimento - marcadamente voltada à exploração de recursos naturais e ao desenvolvimentismo - e a visão de sacralidade de preservação das florestas existente nas comunidades indígenas. Para os índios, seus territórios são ambientes sagrados; para o agronegócio, são imprescindíveis à produção de mercadorias. Retirar a demarcação de terras indígenas da alçada da FUNAI compromete os interesses indígenas e o próprio direito coletivo ao equilíbrio ambiental. 


\section{REFERÊNCIAS BIBLIOGRÁFICAS}

ARAUJO JR., Julio José. Direitos territoriais indígenas: uma interpretação intercultural. Rio de Janeiro: Processo, 2018.

FUNDAÇÃO NACIONAL DO INDIO. Terras indígenas: o que é? Disponível em: http://www.funai.gov.br/index.php/nossas-acoes/demarcacao-de-terras-indigenas?limitstart=0\#.

INSTITUTO SOCIOAMBIENTAL. Terras Indígenas seguem barrando desmatamento, mas situação de algumas áreas é crítica. 07/12/2017. Disponível em: https://terrasindigenas.org.br/pt-br/node/49.

MINISTÉRIO PÚBLICO FEDERAL. 6a Câmara de Coordenação e Revisão - Populações Indígenas e Comunidades Tradicionais. Nota Técnica 01/2019 - 6 ${ }^{\mathbf{a}}$ CCR. Disponível em: http://www.mpf.mp.br/atuacao-tematica/ccr6/documentos-e-publicacoes/publicacoes/notatecnica/2019/nota-tecnica-1-2019-assinada.pdf.

PRESIDÊNCIA DA REPÚBLICA. Medida Provisória 870, de $\mathbf{1}^{\mathbf{0}}$ de janeiro de 2019. Disponível em: http://www.planalto.gov.br/ccivil_03/_ato2019-2022/2019/Mpv/mpv870.htm.

Decreto $\mathbf{n}^{0}$ 5.051, de 19 de abril de 2004 (Promulga a Convenção $\mathrm{n}^{\mathbf{o}} 169$ da Organização Internacional do Trabalho - OIT sobre Povos Indígenas e Tribais). Disponível em: http://www.planalto.gov.br/ccivil_03/_ato20042006/2004/decreto/d5051.htm.

SILVA, Elizângela Cardoso de Araújo. Povos indígenas e o direito à terra na realidade brasileira. Ser. Soc. Soc., n. 133, set./dez. 2018. Disponível em: < 
http://www.scielo.br/pdf/sssoc/n133/0101-6628-sssoc-133-0480.pdf>. Acesso em: 20 mai. 2019.

SUPREMO TRIBUNAL FEDERAL. Petição 3.388-4 RORAIMA. Relatoria Min. Carlos Britto. Julg. 13 de Março de 2009. Disponível em: http://www.stf.jus.br/portal/cms/verNoticiaDetalhe.asp?idConteudo=251738. 